\title{
As Rotas do Tráfico Internacional de Mulheres na Pan Amazônia do Século XXI: Olhares Feministas do Sul Global
}

\author{
Brenda Moreira Marques ${ }^{1}$
}

\section{Resumo}

No bojo do debate sobre o tráfico internacional de mulheres na América Latina no século XXI, analisam-se, através de pesquisa bibliográfica e documental, as rotas de tráfico de mulheres com ênfase na fronteira Pan Amazônica, lançando mão de uma abordagem feminista pós-colonial das Relações Internacionais, uma vez que as mulheres do Sul Global, principais vítimas da prática, podem apresentar suas subjetividades e vozes silenciadas em diferentes dimensões pelo discurso (feminista) atrelado às produções dos grandes centros. De um modo mais preciso, uma leitura feminista pós-colonial do tema se faz necessária, à medida que enfatiza produções subalternas e as especificidades as quais as mulheres do Sul Global estão sujeitas, desconstruindo, portanto, visões dicotômicas que definem essa diversidade de mulheres como sujeito monolítico, frequentemente, na condição de "Outras", pouco civilizadas. Assim, são levadas em conta as marcas históricas trazidas pelo colonialismo, capitalismo, racismo e opressão, que, em diferentes níveis, a depender do contexto e recortes identitários, sustentam estereótipos e vulnerabilidades na vida de muitas mulheres da região. No caso do tráfico internacional de mulheres na localidade, as marcas de colonialidade transitam entre as fronteiras dos países amazônicos, ancoradas em noções de exotismo, hipersexualização, objetificação, selvageria, racialização e violência, marcadores capazes de influenciar relações sociais das mulheres em seu país de origem e destino. Por fim, o trabalho avalia a possibilidade dos trajetos reproduzirem a lógica de exploração ocorrida no passado colonial da região, visto que mulheres latino-americanas podem compor uma força de trabalho em mercados do sul ao norte global.

Palavras-chave: Tráfico internacional de Mulheres, Feminismos Pós-coloniais, Pan Amazônia

\section{Abstract}

At the heart of the debate about the women international traffic in the Latin America during XXI century, we analyze the routes of women traffic, emphasizing the Pan Amazonian boundary, through a post-colonial feminist approach of International Relations, since women from South Hemisphere, main victims of this practice, may present their subjectivities and

\footnotetext{
${ }^{1}$ Discente de Relações Internacionais, UNAMA (Universidade da Amazônia), contato brenda.moreiramarques@gmail.com
} 
voices silenced in different dimensions by the hegemonic (feminist) speech attached to the great centers production, which, many times, may preclude Latin-American subjects in the agenda of the global feminist discussion. Most precisely, a post-colonial feminist reading of the topic is necessary, insofar as this emphasize subordinate productions and specificities, which women from South Hemisphere are susceptible, therefore, the dichotomous vision that define this diversity of women as monolithic subject, frequently, on the condition of "Others", victimized and/or on the way to a most "civilized" position. Conversely, historical marks taken by the imperialism, colonialism, capitalism, racism and oppression are considered, which, in different levels, depending on the context and identity cutting, sustains cultural stereotypes and social vulnerabilities in the life of many women of the region. In the case of international traffic for sexual exploration at the locality, the characteristics of coloniality transit between the boundaries of the amazonian countries, anchored in notions of exotism, hipersexualization, objectification, wildness, racialization and violence, markers able to influence the social relationships of women in their native country and destiny country. Lastly, the work evaluates the possibility of the path on reproducing the exploration occurred during the colonial past of the region, since latin-american women compose a workforce in logic of markets from South to Global South.

Key-words: Post-colonial feminism, Amazon, Trafficking

\section{Introdução}

Inicialmente, pretende-se elucidar a relevância de gênero e feminismo como categorias de análise, considerando a sua construção social e política, nas Relações Internacionais (RI), e, principalmente, para a Pan Amazônia. Isto posto, serão as lentes teóricas do feminismo nas RI que farão uma releitura do campo da Política Internacional, ao inserir em suas interpretações os significados dos discursos, privilégios de masculinidades e relações de poder reveladas através da análise das experiências de mulheres ao redor do globo. Com base nisso, dar-se-á ênfase na temática do tráfico de internacional de mulheres, a partir de um levantamento bibliográfico e documental.

A ênfase em dossiês, relatórios e reportagens tomando como base a região da Amazônia brasileira, deve-se ao fato de o Brasil ser considerado um dos principais países de origem na economia do tráfico de mulheres, ao passo que a Amazônia é considerada a região com maior quantidade de vítimas deste tipo de tráfico, além de abranger a maior quantidade de rotas internacionais do fenômeno, para fins de exploração sexual.

Trata-se de uma questão relevante, que tem sido pouco discutida e aquém de políticas públicas eficazes, tanto nas particulares que caracterizam o fenômeno no contexto Amazônico, quanto em outras regiões do globo. Pois, apesar dos avanços elencados a partir da década de 90 no escopo da ONU para definir e propor medidas internacionais referentes ao tráfico de pessoas, no século XXI o fenômeno se mostra cada vez mais complexo e 
multifacetado, afinal de contas, a compreensão da atividade envolve variáveis sócio e geopolíticas, no campo da segurança internacional, das políticas migratórias, cooperação entre países e na forma como o desenvolvimento (social e econômico) se conecta à estrutura social de cada localidade.

Ademais, considera-se que o desenvolvimento de uma discussão sobre o fenômeno internacional do tráfico de mulheres na região demanda abordagens teóricas das Relações Internacionais que possam considerar os olhares feministas (e de gênero), os quais, além de conceder centralidade à problemática vivida por mulheres amazônidas do Sul Global, busca compreender os contornos particularidades em que a atividade se articula na fronteira dos países pan-amazônicos.

\section{Antecedentes Teóricos}

No campo das Relações Internacionais, a década de 1980 inaugurou uma época de pluralismo intelectual, com o início do diálogo transdisciplinar entre as RI e a Teoria Social, Teoria Política, a Linguística, a Teoria Literária, a teoria pós-moderna, teoria feminista e os estudos pós-coloniais, como crítica às matrizes tradicionais ou racionalistas da disciplina.

Tal debate teve como ponte a ocorrência da "virada construtivista", perspectiva que considera que a política mundial é construída socialmente, ressaltando os elementos intangíveis na ontologia do campo de estudos. Nesta via, mencionam-se alguns intelectuais de destaque, a saber Wendt (1999), Onuf (1989) e Kratochwil (1989), cujas contribuições inauguraram o começo do "Grande Debate" entre positivistas e pós-positivistas (CASTRO, 2012).

Isto é, as abordagens ditas pós-positivistas desafiaram as "as unidades fundacionais do conhecimento - como o sujeito autônomo, o Estado soberano e a teoria unificada" RESENDE, 2009, p. 2), apontando a insuficiência das teorias racionalistas (realistas, liberais, marxistas) e o caráter marginal das perspectivas que evocam novas variáveis de análise, como o poder das ideias, discursos, identidades coletivas e estruturas sociais; parte das quais põe em xeque o entendimento das Ciências como uma produção objetiva e deslocada dos interesses e intenções de seus interlocutores.

Tendo isto em mente, ainda no bojo do "Terceiro Grande Debate", a entrada da corrente feminista nos estudos das RI se deu de forma tardia quando comparada às Ciências sociais de um modo geral. E partiu do questionamento acerca da sub representatividade das 
mulheres na política internacional, que, mais tarde, conduziu a ampliação da agenda de pesquisa do campo, na evolução dos estudos sobre gênero e feminismo inicialmente propostos por autoras como Elshtain (1987), Enloe (1989) e J. Ann. Tickner (1992), através, respectivamente, de suas obras de impacto: Women and war; Bananas, beaches and bases: Making feminist sense of International Politics e Gender in International Relations: Feminist perspectives on achieving global security.

Neste sentido, as perspectivas feministas se fazem sensíveis à análise dos estereótipos socialmente construídos, no exercício de atividades consideradas "apropriadas" a homens e mulheres dentro da política internacional, em que tradicionalmente se atribui construções retóricas de pacifismo, ingenuidade e irrealismo à figura da mulher.

Por um lado, a emergência do "Terceiro Grande Debate" e as agendas pós-século XX mostraram, entre outras coisas, que a formatação das Relações e Política internacional não se restringe às políticas que se dão entre Estados. Em seu livro, Enloe (1989) explica que as perspectivas feministas englobam uma visão que vai da esfera individual à esfera sistêmica, explicitando sobre como macro-estruturas atingem grupos locais e acabam por desenhar uma definição mais ampla da política internacional.

Tais perspectivas colocam as mulheres no centro da abordagem de segurança no globo, ao mesmo tempo em que expõe as várias maneiras que as hierarquias sociais ocorrem nas sociedades e ao longo da história, a fim de compreender primordialmente o que constroem e como vem sendo construídas pela ordem internacional, para que se possam criar formas de desnaturalizar estes processos de privilégio das experiências masculinas ao longo da história, dado que as normas de masculinidade estão contidas na definição de identidades e, por conseguinte, de comportamentos estatais.

De acordo com Monte (2013), o desenvolvimento dos feminismos nas Relações Internacionais pode ser dividido em duas gerações: as feministas de ponto de vista, caracterizadas pela crítica aos conceitos e às práticas das RI que são marcadas por normas de masculinidade e a segunda geração, formada pelas feministas focadas na investigação de casos empíricos, buscando oferecer visibilidade às condições, marginalidades e problemáticas enfrentadas pelas mulheres.

Porém, engana-se quem acredita que a entrada da teoria feminista e das análises de gênero não suscitou debates dos teóricos positivistas acerca da legitimidade de suas contribuições potenciais. Foram autores como Keohane (1998), em Beyond dichotomy: conversations between international relations and feminist theory, que apresentaram um 
discurso resistente quanto aos diferentes feminismos, aceitando, por exemplo, apenas a contribuição daquelas "feministas de pontos de vista" em detrimento das "feministas empiricistas".

Apesar disto, são visíveis as principais contribuições das perspectivas de gênero e feminismo: (i) na reformulação do que se considera "ameaça de estado"; (ii) na exposição das limitações do Estado como provedor de segurança diante da população feminina, a qual compõe a maior parcela de refugiados no mundo; (iii) no entendimento do estupro como arma estratégica de guerra; (iv) na compreensão em como estruturas sociais podem impactar em termos de segurança diferentes grupos de diferentes níveis; e, por fim, (v) em visões alternativas sobre a associação entre opressão, desigualdade de gênero e subcidadania na formatação de crimes de guerra envolvendo escravização/prostituição, tráfico de mulheres e violência de gênero.

Conforme as considerações acima, o mais correto é tratar a teoria em seu sentido plural, visto que o feminismo não é uma vertente homogênea, a notar a pluralidade de perspectivas como o feminismo liberal, o feminismo radical, o feminismo marxista, entre outras. No caso das RI, foi questão de tempo até que outros feminismos - para além das duas gerações - lançassem seus olhares críticos sobre o projeto científico de interpretação do ambiente internacional.

Neste sentido, também como teoria pós-positivista, aparece a relevância dos Estudos Pós-Coloniais, vertente que apresenta uma complexa genealogia, desde a tríade francesa (Cesáire, Memmi e Fannon) da década de 1940, passando pelos Estudos Subalternos de 1970, no campo da crítica literária e dos estudos culturais, com vozes que publicaram poderosas críticas à modernidade e a intelectualidade hegemônica e, posteriormente, foi a década de 1990 que situou o chamado "giro decolonial" na América Latina, perspectiva que almejou produzir um argumento pós e descolonial para e pelo continente latino-americano, partindo da premissa que no Sul Global persistem resquícios de colonialidade (de poder e ser) nos diferentes níveis de vida pessoal e coletiva (BALLESTRIN, 2013).

A este artigo interessa a convergência crítica entre os Estudos pós-coloniais e Feministas, que juntos promoveram uma tentativa de ruptura epistêmica com o mito de história única, haja vista que as perspectivas pós-coloniais apresentam uma abordagem alternativa às dicotomias conceituais do Ocidente, em sua tendência para definir o "lugar" do terceiro mundo nas narrativas universais. Destarte, foi o feminismo que questionou ao viés pós-colonial a exclusão do grupo social das mulheres e do reconhecimento da "colonialidade 
de gênero", termo trabalhado por Lugones (2014), a fim de re-significar as contribuições teóricas.

O feminismo pós-colonial engloba as produções de diversas autoras do Sul Global, com o objetivo de trazer à tona a importância de narrativas locais, reconhecimento de resistências; ao mesmo tempo em que realiza uma dupla crítica: (i) às produções feministas hegemônicas (do Norte Global ou Ocidente), por representarem uma visão arbitrária que converte as "mulheres de terceiro mundo" em uma categoria homogênea e sem poder, vitimizada pelos efeitos dos sistemas econômicos, do colonialismo e patriarcado; e, de outro lado, (ii) a exclusão do grupo social das mulheres e do reconhecimento da colonialidade de gênero, a fim de re-significar as contribuições teóricas das produções pós-coloniais ao longo da história.

São exemplos desta vertente os trabalhos de intelectuais como María Lugones (2014), Mohanty (2008), Femenías (2007), Cumes e Guatemala (2012), Minh-há (1987), Ochy Curiel (2009), e, no Brasil, Lelia Gonzalez (2011), que tem sido apontada como precursora do feminismo afrolatinoamericano.

Em seus artigos, Lugones (2014) defende que os feminismos hegemônicos tratam a opressão no terceiro mundo como uma interação de sistemas econômicos, racializantes e engendrados, em um processo discursivo que traz consigo um legado colonial, uma das marcas do processo de desumanização legitimadora da "missão civilizatória": nas imagens dos colonizados, reduzidos a seres primitivos, agressivamente sexuais, infantis, menos que humanos, com necessidade de serem modificados, em vez de reconhecer que, como proposto em Anibal Quijano (1995 apud LUGONES, 2014, p. 941), neste encontro se caracterizam "seres culturais, política, econômica e religiosamente complexos [...]", cujas especificidades não deveriam ser substituídas, mas encontradas, em contextos de entrecruzamento e diálogo.

Para Mohanty (2008), há uma homogeneização dos discursos a respeito das mulheres de terceiro mundo, ao associar e reduzir sua figura às desigualdades consideradas próprias do Sul do Global, na imagem de mulheres pobres, sem educação, limitadas por tradições e família, o que permite a criação de relações binárias entre "mulheres do sul global" e as "mulheres ocidentais", estas segundas vistas, em suma, como educadas, modernas, no controle de seu corpo e das suas decisões.

Isto posto, esta narrativa hegemônica dos feminismos do Norte, muitas vezes, pode vir a colonizar a produção do conhecimento. Todavia, ao se utilizar o termo "feminismos do norte" aqui não se pretende insinuar que este corresponde a um único feminismo, dado que as 
produções consideradas do Norte englobam, tal como os pensamentos do Sul Global, uma vasta gama de trabalhos e vertentes, a citar as contribuições não apenas das feministas de primeira, segunda e terceira onda, mas às críticas trazidas pelo feminismo negro e queer.

Portanto, pretende-se aqui ressaltar que muitas histórias, localizadas fora do espaço que se define como centro, permanecem invisibilizadas ou têm suas especificidades anuladas em prol de definições universalistas (CURIEL, 2009).

Femenías (2007) ressalta a dupla subalternidade das mulheres e produções latinoamericanas nos discursos hegemônicos, onde diferenças individuais e coletivas são suprimidas, culminando na imagem de "Outras": desvalorizadas, inadequadas e exóticas. Levando-se em conta o lugar periférico dos saberes feministas latino-americanos em relação às produções hegemônicas, a autora questiona a partir de onde devemos exercer o direito à produção de saberes, objetivando uma inclusão dentro da realidade histórica e material do continente.

Para a autora, é necessário revisar e re-significar as contribuições teóricas da região, para então denunciar as dificuldades de visibilidade, audibilidade e transitividade dos saberes produzidos no território latino-americano. Deste modo, cria-se em torno da categoria das "mulheres da América Latina" uma verdadeira comunidade imaginada, sendo primordial o papel das epistemologias alternativas para romper com o etnocentrismo e com o jogo das “identidades negociadas" envolvendo a América Latina, na condição de terra "mestiça", que tem alimentado dicotomias entre o mestiço e diferente/o branco, o impuro/o puro, o ilegítimo e anormal/o legítimo e natural.

Frente a este discurso generalista, Gumes e Guatemala (2012) mencionam a necessidade de humanização das mulheres de origem indígena, que não devem ser vistas apenas como "reserva cultural" ou "peças de um museu", que além de tudo, não constituem um sujeito homogêneo e não se manifestam de forma linear, logo, universalizar a individualidade desse grupo se torna uma forma de sujeitá-las a um papel "menos civilizado", "mais atrasado", lhes atribuindo um lugar inquestionável.

No entanto, não se trata de definir a realidade das mulheres latino-americanas através de um conjunto triplo de opressões (sócio-econômica, de gênero e racial), mas reconhecer tais mulheres como agentes heterogêneos capazes de falar por si mesmas, produzir saberes e decidir a vida que desejam.

Se o feminismo - como teoria política e movimento social - busca a democratização de condições de cidadania e liberdade de todas as mulheres, fugir dessa perspectiva 
emancipatória negligencia o objetivo maior do mesmo, o qual, nas visão de Minh-há (1987), não deve existir para privilegiar as demandas unidimensionais de um seleto grupo de mulheres anglo-saxãs, brancas e de classe média, as quais historicamente tem dominado o registro histórico e o que se considera relevante entre as pautas feministas.

Logo, as vozes de tais produções do Sul Global se fazem importantes, porque questionam o poder do centro a partir de suas margens, com diferentes leituras sobre as significações do poder e fronteira. A partir desta assertiva, Cumes e Guatemala (2012) estabelecem um paralelo com as ideias de Rita Segato (2008), afirmando que não é a repetição dos padrões do passado que compõem a ideia de um povo, mas sim a abertura para deliberação sobre o que e como este povo deseja ser.

Em tratando-se da América Latina, uma das primeiras vozes defensoras de um feminismo afrolatino-americano pertenceu às produções de Lelia Gonzalez, que problematizou a exclusão das mulheres da sociedade brasileira contemporânea e dos anais da história, com atenção especial às negras e indígenas, em seu registro como protagonistas (SANTOS, 2013).

Segundo Lelia Gonzalez e Carlos Hasenbalg (1982), no livro Lugar de Negro, a formação de uma imagem negativa da população negra e mestiça tem sua construção apoiada na estética racista dos meios de comunicação em massa e nas representações populares. Sobre isto, em publicações voltadas à questão de gênero, Gonzalez (2011) alimenta as discussões a respeito da hipersexualização das mulheres de cor, as quais são retratadas na condição de "corpos animalizados" e "burros de carga do sexo".

Como propõe Fontana e Cestari (2014), é através da "memória discursiva" que se perpetuam processos de identificação e estereótipos negativos de racialização. Tal termo foi cunhado por Pecheux (1983 apud FONTANA e CESTARI, 2014) para designar a capacidade de as redes de filiação histórica fornecerem lugar aos processos de identificação. Em seu trabalho, as duas autoras utilizam o termo para descrever os efeitos das redes de memórias dos discursos escravagistas e da colonização, em um processo de construção histórica de um corpo (das mulheres "de cor") que tem sido estereotipado negativamente, na imbricação de traços de ordem racial, cultural, social e de gênero.

No que se refere ao caráter da chamada racialização discursiva, Pinho (2004), em $O$ efeito do sexo: políticas de raça, gênero e miscigenação, oferece contribuições relevantes, considerando o mito fundacional da sociedade (que um dia foi colônia) como carregado de significado sexual. 
Por esta razão, quando se considera o caráter migratório do tráfico internacional de mulheres através da porosidade das fronteiras entre a Pan-Amazônia, vê-se a relevância de olhares que possam descortinar os contextos particulares que constroem as relações sociais (fora do reducionismo cultural), nas quais as mulheres traficadas e prostituídas se encontram, na intersecção de marcadores da diferença acima citados (econômicos, políticos, culturais, psíquicos, subjetivos) em suas condições e experiências no país de origem e nas relações sociais de seu país de destino.

\section{Tráfico de pessoas no ambiente internacional}

Inicialmente, a definição formal do tráfico de pessoas surgiu como um conceito jurídico no século XIX resultante do primeiro instrumento internacional a versar sobre a exploração sexual das práticas de tráfico humano, o Tratado Para a Eliminação do Tráfico de Escravas Brancas (1904), considerando que no período era comum a captura e transporte de mulheres europeias para trabalhar em condições de prostituição nas Américas e outras localidades, a serviço das demandas dos imigrantes do sexo masculino (MENEZES, 1996).

Até atingir a definição que hoje é amplamente aceita na comunidade internacional, cabe destacar, alguns marcos jurídicos, a exemplo da Convenção para Supressão do Tráfico de Pessoas e da Exploração da prostituição ocorrida em 1949, a Conferência Mundial de Direitos Humanos de 1993, o Programa de Ação da Comissão de Direitos Humanos para a Prevenção do Tráfico de Pessoas e a Exploração da Prostituição, e mais recentemente, o Protocolo Adicional à Convenção das Nações Unidas Contra o Crime Organizado Transnacional relativo à Prevenção, à Repressão e à Punição do Tráfico de Pessoas (2000), conhecido como Protocolo de Palermo, documento que estabeleceu a primeira definição internacional aceita do crime, além de ter estabelecido padrões mínimos de prevenção, repressão ao tráfico e proteção às vítimas.

Em outras palavras, a ratificação generalizada do Protocolo de Palermo (2000) representou um importante avanço na luta contra o crime organizado transnacional, visto que o crime do Tráfico de Pessoas se tornou uma tipificação criminal a ser inclusa na legislação nacional dos países, o que reforçou as possibilidades de cooperação internacional no combate ao crime, através da criação de mecanismos de assistência e denúncia por parte dos paísessignatários. Segundo a definição do documento: 
Trafico de pessoas deve significar o recrutamento, transporte, transferência, abrigo ou recebimento de pessoas por meio de ameaça ou uso da força ou outras formas de coerção, de rapto, de fraude, de engano, do abuso de poder ou de uma posição de vulnerabilidade ou de dar ou receber pagamentos ou benefícios para obter o consentimento para uma pessoa ter controle sobre a outra, para o propósito de exploração, inclui, no mínimo a exploração da prostituição, ou outras formas de exploração sexual, trabalho ou serviços forçados, escravidão ou praticas análogas à escravidão, servidão ou a remoção de órgãos (PROTOCOLO DE PALERMO, 2000).

Dito isto, torna-se claro que parte da importância do Protocolo de Palermo (2000) se encontra no fato de que este permitiu o reconhecimento de uma ampla variedade de condições de manifesto do crime. Pois, a grosso modo, dados estatísticos sugerem que cada região do globo apresenta diferentes padrões da atividade: para o Norte da África e Oriente Médio, o principal propósito do crime se dá pelo trabalho forçado 44\%; para a África Subsaariana o número aumenta para 43\%; na América do Norte cerca de 55\% da atividade tem como fim a exploração sexual; na América Central e Caribe o número aumenta para 57\% para a exploração sexual; o mesmo número se repete para a exploração sexual na América do Sul, em 57\%; já na Europa Oriental e na Ásia Central, destaca-se 64\% dos casos de tráfico reportando trabalho forçado; enquanto a Europa central registra $66 \%$ dos casos de tráfico voltados à exploração sexual (UNODOC, 2016).

Dessa forma, há uma profunda dificuldade para definir e detalhar uma visão acerca do fenômeno do ponto de vista geográfico, devido à vasta variedade de países envolvidos em meio aos trajetos de rotas em prol do tráfico de pessoas. Portanto, não à toa, trata-se de uma das categorias de crime de caráter transnacional que mais cresce no sistema internacional, atrás apenas da indústria do tráfico de armas e de drogas; o que também sugere que as indústrias globais do sexo e do tráfico de pessoas cresceram frente às dinâmicas da globalização, que criou condições favoráveis para o aprimoramento e o crescimento das formas de articulação da prática, pois tornou as vítimas "mais fáceis de procurar, transportar e explorar" (KABANCE, 2014).

\section{Perspectivas históricas e as rotas de tráfico na Pan Amazônia}

No que se refere à Amazônia, as primeiras demonstrações do fenômeno do tráfico humano ocorreram durante o período de colonização, sob a tutela de invasões portuguesas, espanholas e, em menor grau, inglesa, francesa e holandesa. Por conseguinte, neste regime ocorreu a captura de mais de 300.000 indígenas, para escravidão, seguido do tráfico de 1/3 destes para fins laborais (RIBEIRO, 1995). 
Como aponta Chiarotti (2002), observa-se uma forte associação da raiz do tráfico humano à matriz colonial dos países, com ênfase nas mulheres africanas e indígenas, que eram traficadas como escravas frequentemente dentro do triplo propósito: o de mão de obra gratuita, a reprodução de escravos para a produção de mais mão de obra e servir como objeto sexual, a disposição "do seu patrão" no papel de concubina.

Smith $(2009$, p. 4) ressalta o importante papel da ocupação histórica do território para a construção de uma cultura permissiva à exploração da mulher na região, "visto que as principais ações voltadas para o desenvolvimento regional se pautavam no trabalho do homem, ocasionando ocupações para servir às necessidades deles”.

Mas, por outro lado, se a partir do século XIX, com o fim da colonização os principais eventos econômicos na região se manifestaram através de novas dinâmicas: (i) a economia e decadência da borracha; (ii) os projetos de desenvolvimento (1950); (iii) novos processos de “colonização" (1970); e, na atualidade, (iv) a continuação dos projetos de incorporação de capital e integração econômica; entende-se que tais dinâmicas não só mantiveram uma herança colonial como não impediram que o crime do tráfico de pessoas assumisse novas formas.

Entre as causas da persistência da atividade na realidade de mulheres da região está o fato de ocorrer um processo de invisibilização da mulher amazônida como ente nos projetos de desenvolvimento e nas políticas sócio-econômicas locais, em uma realidade permissiva ao tráfico e à exploração sexual, na naturalização da prática de migração interna e externa pela fronteira Pan Amazônica desde o passado na associação com as demandas de “(...) seringueiros, garimpeiros, trabalhadores de construção e marinheiros, para ocupar os serviços por eles desejados (...) muitas vezes através de aliciadores e traficantes” (HAZEU, 2008, p. $57)$.

Por outro lado, para além da falha dos projetos desenvolvimento, a vastidão territorial entre os países limítrofes torna a Pan Amazônia mais propensa à prática, tanto do tráfico de mulheres, quanto aos episódios de imigração ilegal, principalmente nas regiões formadas por garimpos, boates, prostíbulos e núcleos urbanos relativamente recentes de Grandes Projetos mineiros, energéticos e de agricultura.

De acordo com a Tabela 1, na região Pan Amazônica, as rotas mais frequentes se dão entre os seguintes países: i) Brasil, Peru e Bolívia para fins sexuais em boates e prostíbulos; ii) entre Brasil e Guiana Francesa, muitas vezes traficadas para o comércio sexual nos garimpos; iii) entre diferentes estados da Amazônia brasileira, em fluxos significativos de 
mulheres para o Suriname, Guiana Francesa e Venezuela em direção à casas de prostituição e garimpos; iv) entre Colômbia e Peru, v) Guiana e Venezuela (ENAFRON, 2014; HAZEU, 2008; SMITH, 2009).

TABELA 1. AS ROTAS DE TRÁFICO INTERNACIONAL NA PAN AMAZÔNIA

\begin{tabular}{|c|c|c|}
\hline PAÍS DE ORIGEM & PAÍS INTERMEDIÁRIO & ROTA FINAL \\
\hline BRASIL (Pará) & $\begin{array}{l}\text { SURINAME } \\
\text { (Paramaribo, Nickerie e regiões de } \\
\text { garimpo) }\end{array}$ & $\begin{array}{l}\text { HOLANDA, SUIÇA, PORTUGAL, } \\
\text { ESPANHA } \\
\text { (HAZEU, 2008; SMITH, 2010) }\end{array}$ \\
\hline $\begin{array}{l}\text { BRASIL } \\
\text { (Manaus - Tabatinga) } \\
\text { BRASIL } \\
\text { (Manaus - Tabatinga) } \\
\text { BRASIL } \\
\text { (Roraima - Boa Vista) }\end{array}$ & $\begin{array}{l}\text { PERU (Iquitos), VENEZUELA } \\
\text { SURINAME, GUIANA }\end{array}$ & $\begin{array}{l}\text { PERU } \\
\text { (Caballococha) } \\
\text { PORTUGAL, } \\
\text { AMÉRICA DO NORTE ESPANHA, } \\
\text { HOLANDA, } \\
\text { ESPANHA PORTUGAL, } \\
\text { (UOL, 2016; AMAZONIA.ORG, } \\
\text { 2012) }\end{array}$ \\
\hline COLÔMBIA (Letícia) & & $\begin{array}{l}\text { PERU (Caballococha), BRASIL } \\
\text { (Manaus - Tabatinga) } \\
\text { (REPORTAGEM DO G1, 2016; EL } \\
\text { TELÉGRAFO, 2016) }\end{array}$ \\
\hline $\begin{array}{l}\text { COLÔMBIA } \\
\text { (Cartagena, Medellin, Letícia) } \\
\text { BRASIL } \\
\text { (Manaus - Tabatinga) }\end{array}$ & & $\begin{array}{l}\text { PERU } \\
\text { (Iquitos - Lima) } \\
\text { PERU (Iquitos) } \\
\text { (CAPITAL HUMANO Y SOCIAL } \\
\text { ALTERNATIVO, 2012) }\end{array}$ \\
\hline $\begin{array}{l}\text { BRASIL } \\
\text { (Roraima e Manaus - Rorainópolis, } \\
\text { Caracaraí, Boa Vista e Pacaraima) }\end{array}$ & $\begin{array}{l}\text { VENEZUELA } \\
\text { (Santa Elena de Uairén, Km 88, El } \\
\text { Callao, El Dorado, Tumeremo, } \\
\text { Puerto Ordaz, Puerto La Cruz e } \\
\text { Margarita), GUIANA, SURINAME }\end{array}$ & $\begin{array}{l}\text { PORTUGAL, ESPANHA } \\
\text { HOLANDA } \\
(\text { OLIVEIRA, 2008) }\end{array}$ \\
\hline $\begin{array}{l}\text { BRASIL } \\
\text { (Amapá - Oiapoque) } \\
\text { BRASIL } \\
\text { (Roraima - Boa vista) } \\
\text { BRASIL } \\
\text { (Roraima - Guajará Mirim) }\end{array}$ & $\begin{array}{l}\text { GUIANA FRANCESA } \\
\text { (Cayena, São Jorge) } \\
\text { VENEZUELA } \\
\text { (Santa Helén de Uieren) } \\
\text { BOLÍVIA } \\
\text { (Cojiba, Guayaramirim) } \\
\end{array}$ & \\
\hline GUIANA & VENEZUELA & \\
\hline
\end{tabular}

Fonte: Elaboração nossa a partir de Enafron (2014); Hazeu (2008); Smith (2009).

\section{Aportes feministas pós-coloniais acerca do tráfico Internacional de mulheres na região:}

\section{Quanto à colonização de experiências}

A presente pesquisa teve início a partir do questionamento sobre como uma perspectiva feminista pós-colonial poderia avaliar as rotas contemporâneas de tráfico internacional de mulheres, tendo como referencial a região Amazônica. Em princípio, uma rasa leitura (bibliográfica) atrelada à uniformidade de relatórios gerais e das inúmeras reportagens sobre o tema - disponíveis na mídia - apontavam a hipótese de que as rotas 
internacionais obedeciam diretamente e em maior número aos trajetos Pan Amazônia Europa (em especial Portugal, Espanha, Holanda e Alemanha).

Contudo, ao longo do trabalho verificou-se uma perspectiva ainda mais complexa no que se refere às rotas de tráfico de mulheres. Primeiramente se considera que a hipótese inicial levantada pelo artigo se mostra insuficiente em retratar a região Amazônica, para avaliar o fenômeno em sua totalidade de aspectos e condicionantes regionais, dado que se verificou que as rotas mais numerosas e comuns não possuem como destino final, do ponto de vista prático, os países europeus.

Pelo contrário, a perspectiva de chegada a tais países é apenas uma possibilidade de destino final, que se concretiza em um número reduzido de casos, o que, portanto, não reflete a totalidade do fenômeno. Por outro lado, ocorre que as rotas de tráfico internacional se concentram dentro do próprio continente latino-americano, pela facilidade de meios de circulação intracontinental (no âmbito da Pan Amazônia, são as rotas: Brasil-Peru, BolíviaBrasil, Colômbia-Peru, Colômbia-Brasil, Brasil-Suriname, Brasil-Guiana, Venezuela-Brasil, Bolívia-Venezuela, Peru-Suriname, Peru-Brasil), bem como a fiscalização precária de fronteiras.

Em segundo lugar, durante a pesquisa documental, observou-se uma uniformidade discursiva nas fontes de dossiês, relatórios e, principalmente, reportagens. Esta convergência de dados ou uniformidade se manifestou mais marcantemente em dois aspectos: i) quanto ao perfil da vítima; ii) as principais rotas intracontinentais e fora do continente sul-americano.

Esta assertiva é verificável sob diversos aspectos: (i) a realidade do fenômeno é expressa em um corpus documental com recorte geográfico amplo, englobando a América Latina como um todo, com pouco enfoque nas particularidades dos países Amazônicos, ainda que o território compreenda o registro mais significativo em números de rotas do crime no continente; (ii) há um número inexpressivo de publicações que investiguem o fenômeno, tendo caráter cultural e identitário regional como variáveis preponderantes nas políticas públicas de enfrentamento, que possam desnaturalizar a prática do crime na região; (iii) foram percebidas assimetrias nos resultados entre as produções documentais globais e em relação às pesquisas de recorte geográfico e teórico regional.

Do ponto de vista acadêmico, situar a Pan Amazônia em relação aos imperialismos dos projetos coloniais não é o suficiente, visto que a região não deve ser definida pela e a partir de uma perspectiva externa. Logo, compreender a região implica perceber que quando se fala em fronteira Pan Amazônica é necessário desconstruir o lócus tradicional, que vê a fronteira 
como um dado empírico capaz de determinar a "vocação" do território, centrado em diferentes em terras livres, ricas e desabitadas (RABELO, 2013).

Tal perspectiva que compreende uma violência simbólica das relações de poder intracontinentais, ao excluir a existência da pluralidade de populações que, em virtude da variedade de projetos de desenvolvimento (grandes complexos de barragens, regiões de garimpo, mineradoras, latifúndios), não é vista como prioridade nos olhares das políticas públicas.

Se, por um lado, a própria população enfrenta estes múltiplos desafios, por outro, um olhar mais sensível sobre as organizações sociais e as relações identitárias permitem afirmar que as áreas aquém destes projetos de desenvolvimento e da iniciativa de capital, passam por processos ainda mais intensos de pauperização, com a subsequente formação de mão de obra autônoma, suscitando novos processos migratórios em direção às áreas de fronteira, o que reproduz relações de poder provenientes de regiões vizinhas intensamente urbanizadas.

Retomando a fala de Carvalho (2012), ao citar que sem a Pan Amazônia não há possibilidade de integração latino-americana; no que concerne às temáticas do tráfico internacional de mulheres e mercados globais de sexo, é igualmente inútil entender o fenômeno sem simultaneamente juntar esforços para entender a complexidade cultural, social e econômica que forma a fronteira Pan Amazônica, bem como as condição das mulheres e homens latino-americanos, sem impor a nenhum um lugar conceitual fixo e categorizado.

É Mohanty (2008) quem propõe uma prática que opte pela descolonização discursiva dos feminismos hegemônicos, ao considerar as mulheres dentro e através de suas estruturas sociais em nível local, entendendo aí que suas experiências e resistências se modificam em função do valor social, atrelado a aspectos culturais e particulares, das formas de opressão às quais podem estar expostas (racial, social, sexual, etc). Portanto, a descolonização das experiências das realidades materiais destas mulheres se torna um fator crucial para a correta interpretação do fenômeno e suas maneiras de articulação.

Trazendo à luz do que foi proposto por Lugones (2014), no caso do tráfico na Pan Amazônia tais critérios e as avaliações tradicionais acabam por reduzir ou ignorar todas as diversidades da região, ao situá-las dentro da mesma categoria, na imagem de subdesenvolvimento e dependência das intervenções, olhares e privilégios que o Primeiro mundo e suas mulheres possuem, em consonância com o que Gayatri Spivak (ano?) propõe, que a fabricação de identidades "estrategicamente essencialistas" podem se tornar uma arma política; de forma que o presente artigo cita seu potencial para obstruir a construção de 
políticas públicas efetivas de enfrentamento e prevenção ao tráfico e exploração sexual de mulheres.

Sobre isto, Mohanty (2008) indica o colonialismo contido na suposição de que o patriarcado atua de forma universal sobre um grupo ou região. Desta forma, ao condicionar às vítimas de tráfico humano da Amazônia como um grupo de mulheres sem poder, ignorante, restrito a auto-representações de pobreza e visões domésticas primitivas, acaba-se as convertendo em "objetos que se defendem" e se universaliza a noção de que todos os homens da região cumprem o papel de "sujeitos que exercem violência" sobre seus corpos e suas vidas, binarismos que, por não permitirem uma visão detalhada e local acerca do problema, não fornecem as ferramentas necessárias para transformar a realidade considerada, além do fato de muitas vezes não corresponderem ao que de fato acontece.

Um exemplo disto é o fato de que, diferente do passado histórico (colonial e do século XIX) quando os homens eram os principais traficantes e aliciadores, na atualidade do crime, verifica-se principalmente a presença de mulheres nesta função, muitas vezes amigas, parentes ou conhecidas, também trabalhadoras do sexo e vítimas do tráfico e/ou contrabando de imigrantes. Logo, desde este dado, a dicotomia entre homens (como grupo detentor majoritário do poder de decisão) e mulheres (grupo que carece de poder) na região começa a se tornar pouco conclusiva.

Em sua fala, Gonzalez (2011, p. 5) explica "nós mulheres e não-brancas, fomos 'faladas', definidas e classificadas por um sistema ideológico de dominação que nos infantiliza". Daí, infere-se também que nesta condição de "falar pelo outro", muitos grupos de mulheres vítimas do tráfico passam a ser infantilizados, reduzidos a uma condição ausente de sua presença, de falas e trajetórias subjetivas anuladas, dentro de relatórios, políticas e organizações internacionais.

Ainda nesta visão, os gestos e o produzir dessas mulheres traficadas são digno de atenção genuína, uma vez que suas trajetórias de vida e seus projetos futuros não são homogêneos e não são trajetórias necessariamente inseparáveis dos produtos históricocoloniais da região. Para Mohanty (2008) e Lugones (2014) é um erro atribuir às mulheres do terceiro mundo os mesmos problemas, necessidades, interesses e objetivos, visto que as políticas de desenvolvimento não afetam de forma igual a cada um dos diversos grupos que compõem a categoria, haja vista que envolve uma complexa interação entre classe, cultura, religião e outras instituições e marcos de referências e mobilizações em suas relações sociais. 
Esse afastamento na organização de dados de relatórios e no próprio tratamento impessoal às vítimas as coloca na condição de seres imóveis e passivos diante das circunstâncias em que estão inseridas e nas quais a prostituição e a frequente violência (associada ao tráfico) se desenrola.

Daí se entende a importância de enfatizar os olhares sob contextos específicos do fenômeno e as produções locais, como formas de articular estratégias de cooperação que tenham meios suficientes para revelar e compreender - com uma visão de dentro das estruturas sociais e das mulheres e homens que a formam - as potencialidades e limitações da região, dos governos e dos instrumentos internacionais, na tentativa crescente de diminuir os números de mulheres traficadas e remediar a situação precária em que muitas se encontram em contextos imigratórios.

\section{Quanto às identidades negociadas}

Quando o presente artigo comenta a existência de identidades negociadas, faz-se referência, em parte, aos estereótipos - que se manifestam sob discursos nocivos - que se encontram presentes nas fronteiras intracontinentais, no Suriname, Equador, Brasil, Bolívia, Venezuela, Guianas, Peru e Colômbia, registrados desde a forma como as imigrantes (e por vezes traficadas) são vistas, independente de estarem inseridas na indústria do sexo.

Por conseguinte, criou-se no imaginário europeu e brasileiro traços de mulheres amazônidas como exóticas, belas, lascivas e selvagens, o que contribuiu à introdução da prática do tráfico de mulheres na região, onde "essa ideia étnica, da índia lasciva, faz com que a sociedade, enxergue o tráfico como uma coisa natural" (CALDAS, 2016 apud AMAZONIA, NOTÍCIA E INFORMAÇÃO, 2016).

Em entrevista, a antropóloga Iraildes Caldas (2016 apud AMAZÔNIA, NOTÍCIA E INFORMAÇÃO, 2016) destaca o tráfico sexual na Pan Amazônia como um fenômeno além da questão de pobreza, visto que na região a questão indígena e étnica se posiciona nas heranças patriarcais e coloniais. Além disso, há a tendência (histórica) regional de "doação de moças e crianças" por famílias de origem ribeirinha, interiorana ou periférica para responsáveis da "cidade grande", para que essas meninas e jovens possam ter uma vida melhor, contextos estes que frequentemente reverberam na naturalização da sua exploração servil e sexual.

Sobre esta naturalização da prática e generalização de esteriótipos, aplica-se o pensamento de Femenías (2007), sobre como o discurso ocidental desloca as mulheres da América Latina a uma condição geográfica e economicamente excêntrica e descentrada. Sendo assim, torna-se um problema ainda mais profundo, quando as políticas anti-tráfico e as 
políticas anti-migratórias os países - em especial os latino-americanos - não se preocupam com a conversão da construção imaginada destas "Outras" latino-americanas, inadequadas diante do desenvolvimento, amazônidas, em sujeitos-agentes de suas vidas, para além dos estereótipos marginais a que as vítimas se associam. Assim, esta sujeito-agente será interprete da sua própria identidade mestiça, para desconstruir "verdades naturalizadas".

O estudo etnográfico de Olivar et al (2015) sintetiza na prática a definição do sistema colonial de gênero proposta por Lugones (2007), voltada aos contextos Pan Amazônicos, com marcos de referência intrafronteiriços na visão de mulheres latino-americanas situadas e socialmente julgadas em diferentes níveis pela sua beleza, "selvageria", "aparência indígena", o que surge como partes de identidades subvalorizadas localmente e, em alguns casos, hipervalorizadas em contextos externos.

Vê-se também uma espécie de supervalorização de mulheres de peles claras no que se refere às demandas da indústria do tráfico de mulheres, o que pode, muitas vezes, representar a construção negativa sobre as "mestiças" que María Lugones denuncia. Neste caso, a palavra deixa de ter um significado biológico e passa a abranger uma significação cultural, onde as políticas de mestiçagem implicam um caráter de "não pertencimento" simbólico, uma vez que a noção de "pureza identitária" resgata distinções que separam as mulheres em categorias de "puras" e "impuras", invocando fortes resquícios de discriminação que remontam o passado colonial. Entretanto, a própria mestiçagem pode ser entendida por outros grupos como uma forma simbólica de resistência às construções sociais de pureza étnica.

Pode-se interpretar esta questão a partir das ideias de Ochy Curiel (2007) e Rita Segato (2008), as quais descortinam "os modos que a mestiçagem colonial e pós-colonial se relacionam com a rigidez racista de nossas estruturas sociais", que apesar de se nomearem igualitárias, apresentam mecanismos que encobrem o fato de a exclusão e discriminação de gênero ser potencializada por fatores étnicos e culturais.

Isto influi diretamente na noção de que as mulheres mais pobres, de trajetória marginalizada, são as vítimas do tráfico humano, são as que exercerão a prostituição em outros países. Logo, em consonância com a proposta de Gonzalez (2011, p. 14), "tratar da divisão sexual do trabalho sem articulá-la com seu correspondente em nível racial, é recair numa espécie de racionalismo universal típico de um discurso masculinizado e branco".

Ao adentrar mais ainda no campo pós-colonial dos feminismos latino-americanos em sua intersecção com a diáspora negra, diz-se que as afrodescendentes eram e ainda são marcadas pela visão difundida de seus corpos e vida dentro das fronteiras na realidade de cada 
país quanto em contextos migratórios, em sociedades que designam papeis às mulheres aqui ditas amefricanas e ameríndias, moldadas a uma imagem perfeita nas atividades domésticas, artísticas, servis, como se este fosse seu único lugar de direito.

Da mesma forma, Curiel (2007) aponta a existência de uma estrutura de alienação, cuja função resgata o caráter estrangeiro inquietante atribuído à folclorização e exoticidade da figura negra, que no que se refere a regiões dotadas de passado colonial, forma-se a noção de uma mistificação compensatória, na celebração do "primitivo".

Configura-se, neste ponto, a racialização ou memória discursiva de Pinho (2004) e Fontana e Cestari (2014), como fatores preponderantes às dificuldades enfrentadas pelas vítimas de tráfico humano quando situadas nas realidades de seus países de destino e de origem. Ambos os termos expressam um processo de construção histórica do corpo colonial das mulheres de cor, através de identificações fornecidas por redes de filiação, que tendem a "usar" a imagem do corpo colonial em uma noção de oferta e demanda, na comercialização das identidades e símbolos nacionais de países como o Brasil, Colômbia, Suriname, Peru, Venezuela, dentro das fronteiras do continente sul-americano e fora destas, em países onde as mulheres imigrantes são exploradas (e traficadas) ou irão exercer a prática da prostituição na Europa.

Nos contextos latino-americanos, em que é frequente o trânsito do tráfico das mulheres que irão se prostituir e ser prostituídas em garimpos, regiões de grandes empreendimentos, clubes e boates, muitas vezes com o objetivo de exercer a profissão temporariamente para seguir em direção aos seus países de destino, onde o "ser mestiça", "ser negra", "ser indígena", assim como em seus países de origem, também compõem parte de um processo social que constrói identidades.

\section{Considerações finais}

Ainda que as rotas internacionais de tráfico na Pan Amazônia não representem com exatidão a repetição da hipótese de colonialidade tradicionalmente enunciada (com os mercados e suas forças de trabalho a serviço do Norte Global), isto não quer dizer que a perspectiva pós-colonial deixe de ser uma interpretação adequada, posto que o processo de expansão capitalista na região trouxe contornos diferenciados dentro de suas próprias fronteiras, ao se notar, por exemplo, que as tentativas de integração da Pan Amazônia tem facilitado à fragmentação social, econômica e territorial entre os países e os territórios subnacionais, dado que essas iniciativas priorizam territórios estratégicos ao capital, na sua 
conexão com mercados globalizados, o que secundariza outras partes do território e aumenta o fosso das desigualdades para as populações tradicionais.

Ademais, o presente trabalho reconhece as limitações de pesquisa no que se refere a captura de informações e fontes para abordar a questão do tráfico internacional de mulheres, devido à carência de dados atualizados e pesquisas voltadas à região Amazônica. Por outro lado, espera-se que os argumentos aqui levantados desencadeiem novos questionamentos que possam enriquecer a produção de saberes e a noção de que reducionismos culturais e categorizações têm a capacidade de criar barreiras no entendimento de problemáticas no cenário internacional, a exemplo do tráfico de pessoas e os mercados de sexo articulados entre as fronteiras da Pan Amazônia.

\section{Referências Bibliográficas}

AMAZONIA, NOTÍCIA E INFORMAÇÃO. Como acontece o tráfico de mulheres na Amazônia? [9 de março de 2016]. Disponível em: http://amazonia.org.br/2016/03/comoacontece-o-trafico-de-mulheres-na-amazonia/ Acesso em: 23 nov, 2016.

BALLESTRIN, Luciana. América Latina e o giro decolonial. Revista Brasileira de Ciência Política, no 11, Brasília, 2013.

CAPITAL HUMANO Y SOCIAL ALTERNATIVO. La trata de personas en la triple frontera Peru-Brasil-Colômbia, 2012. Disponível em:

http://www.chsalternativo.org/informes-y-estudios/371-informe-la-trata-de-personas-en-latriple-frontera-peru-brasil-colombia/file. Acesso em: 25 set, 2016.

CARVALHO, Guilherme. Grandes projetos de infraestrutura, conflitos e violação de direitos na Pan Amazônia. Revista Latinoamericana de Derecho y Políticas Ambientales. Peru: Ano 2, No. 2, Agosto de 2012.

CASTRO, Thales. Teoria das Relações Internacionais. Brasília: Editora FUNAG, 2012.

CHIAROTTI, Susana. Trata de Mujeres: Conexiones y Desconexiones con Migración y Derechos Humanos. Conferencia Hemisférica sobre Migración Internacional: Derechos Humanos y Trata de Personas. Santiago de Chile, 2002.

COSTA, Rosa. Brasil tem 241 rotas de tráfico de pessoas, diz ONU. Estadão, São Paulo, 6. Nov. 2012.

CUMES, Aura Estela; GUATEMALA, Maya-Kaqchikel. Mujeres indígenas, patriarcado y colonialismo: un desafía a la segregación comprensiva de las formas de dominio. Anuario Hojas de Warmi "Seminario: Conversatorios sobre Mujeres y Género, Universidad de Murcia”, Espanha: n 17, 2012. 
CURIEL, Ochy. Descolonizando el feminismo: una perspectiva desde America Latina y el Caribe". In: PRIMER COLOQUIO LATINOAMERICANO SOBRE PRAXIS Y PENSAMIENTO FEMINISTA, Buenos Aires, 2009.

ElSHTAIN, Jean Bethke. Women and war. Chicago: University of Chicago Press, 1987.

EL TELÉGRAFO, Colombia desbarata red de trata de ninas para prostituicion en Peru y Brasil. Disponível em: http://www.eltelegrafo.com.ec/noticias/mundo/9/colombia-desbaratared-de-trata-de-ninas-para-prostitucion-en-peru-y-brasil Acesso em: 28 set, 2016.

ENAFRON. Diagnóstico sobre o Tráfico de Pessoas nas áreas de fronteira. SNJ, São Paulo, 2014.

ENLOE, Cynthia. Bananas, beaches and bases: Making feminist sense of International Politics. California: University of California Press, 1989.

FEMENÍAS, Maria Luísa. Esbozo de un feminismo latino-americano. Estudos Feministas, Florianópolis, 15(1): 280, janeiro-abril, 2007.

FONTANA, Mónica G. Zoppi; CESTARI, Mariana Jafet. Cara de empregada doméstica: discursos sobre os corpos de mulheres negras no Brasil. $8^{\circ}$ IGALA CONFERENCE, Canadá, 2014.

GONZALEZ, Lelia; HAZENBALG, Carlos. Lugar de Negro. Rio de Janeiro: Ed. Marco zero ltda, 1982.

GONZALEZ, Lélia. Por um feminismo afrolatino-americano. Caderno de formação política do ciclo palmarino, São Paulo: $n^{\circ} 1,2011$.

G1, Colômbia desarticula rede de tráfico de menores para prostituição no Brasil. Disponível em: http://g1.globo.com/mundo/noticia/2016/11/colombia-desarticula-rede-de-trafico-demenores-para-prostituicao-no-brasil.html. Acesso em: 2 out, 2016.

G1. Colômbia desarticula rede de tráfico de menores para prostituição no Brasil. Disponível em: http://g1.globo.com/mundo/noticia/2016/11/colombia-desarticula-rede-detrafico-de-menores-para-prostituicao-no-brasil.html. Acesso em: 2 dezembro 2016.

HAZEU, Marcel (Coord.). Pesquisa trinacional sobre tráfico de mulheres do Brasil e da República Dominicana para o Suriname: uma intervenção em rede. ONG Sodireitos, Belém, 2008.

KABANCE, Karie. The globalization of sex trafficking. International Affairs: directed research project, Oxford, 2014.

KEOHANE, Robert. Beyond Dichotomy: Conversations between International Relations and Feminist Theory. International Studies Quarterly, Reino Unido: nº 42, 193-198.

LUGONES, María. Rumo a um feminismo descolonial. Revista Estudos Feministas, Florianópolis, 2014.

MENEZES, Lená Medeiros de. Os indesejáveis: Desclassificados da modernidade. Protesto, crime e expulsão na capital federal (1890-1930). Rio de Janeiro: Ed. UERJ, 1996. 
MINH-HÁ, T. Difference: A special third world women issue. Feminist Review, Reino Unido: $\mathrm{n}^{\circ} 25,1987$.

MOHANTY, Chandra Talpade. "Bajo los ojos de occidente". In: NAVAZ, Liliana Suarez; HERNÁNDEZ, Aída. Descolonizando el feminismo: Teorías y prácticas desde los margenes. Madrid: Editora Cátedra, 2008.

MONTE, Isabela Xavier do. O debate e os debates: abordagens feministas para as Relações Internacionais. Rev. Estud. Fem. Florianópolis, vol.21 no.1, Jan./Apr. 2013.

OLIVAR, José Miguel Nieto; CUNHA, Flávia de Melo da; ROSA, Patrícia Carvalho. Presenças e mobilidades transfronteiriças entre Brasil, Peru e Colômbia: o caso da migração peruana na Amazônia brasileira. TOMO, nº 26 - Núcleo de Estudos Pagu, Amazonas, 2015.

OLIVEIRA, Rafael da Silva. Um olhar sobre as redes de prostituição e tráfico de mulheres na fronteira Brasil-Venezuela a partir das rodovias BR-174 e Troncal 10. X Colóquio

Internacional de Geocrítica, Diez Años de câmbios em el mundo, em la geografia y en las ciencias sociales (1998-2008), Barcelona, 2008.

PINHO, Osmundo de Araujo. O efeito do sexo: políticas de raça, gênero e miscigenação. Cadernos Pagu, nº 23, p. 89-119, 2004.

PROTOCOLO DE PALERMO, 2000. Marco legal. Disponível em:

https://www.unodc.org/lpo-brazil/pt/crime/marco-legal.html. Acesso em: 23 set, 2016.

RABELLO, Antônio Cláudio. Amazônia: uma fronteira volátil. Estud. av., São Paulo: v. 27, n. 78, p. 213-235, 2013.

RESENDE, Erica Simone Almeida. O “eu” e o "outro" nas práticas de política externa: Como resistir à produção da outricidade nos processos de Construção de conhecimento nas relações internacionais?. VIII Jornadas de Sociología de la Universidad de Buenos Aires. Asociación Latinoamericana de Sociología, Buenos Aires, 2009, p. 2.

REVISTA FÓRUM. Pan-Amazônia: pontos cegos na fronteira facilitam tráfico de mulheres. Disponível em: http://www.revistaforum.com.br/2012/02/08/panamazonia_pontos_cegos_na_fronteira_facilitam_trafico_de_mulheres/. Acesso em: 13 jan, 2017.

RIBEIRO, Darcy. O povo brasileiro: formação e sentido do Brasil. São Paulo: Global Editora e distribuidora ltda, 1995.

SANTOS, Luana Diana. Por um Feminismo Plural: escritos de Lélia Gonzalez no Jornal Mulherio. Gênero na Amazônia, Belém, n. 4, jul./dez., 2013.

SMITH, Andreza do Socorro Pantoja de Oliveira. Migração feminina e o Tráfico de mulheres na Amazônia. V Encontro Anual da ANDHEP, Grupo de trabalho: Marcadores sociais da diferença e direitos humanos, Belém, 2009.

SPIVAK, Gayatri. Pode o subalterno falar?. Belo Horizonte: Editora UFMG, 2010.

TICKNER, J. Ann. Gender in International Relations: Feminist Perspectives on Achieving Global Security. New York: Columbia University Press, 1992. 
VIOLÊNCIA DE GÊNERO Y TRATA DE PERSONAS. Disponível em:

http://www.amazonia-andina.org/sites/default/files/fasciculo_violencia_version_final.pdf. Acesso em: $15 \mathrm{dez}, 2016$. 